\title{
Precision Dicing of Optical Materials
}

\author{
L. G. Carpenter, C. Holmes, P. A. Cooper, J. C. Gates and P. G. R. Smith \\ Optoelectronics Research Centre, University of Southampton, Highfield, Southampton, \\ Hampshire, SO17 1BJ, UK
}

\begin{abstract}
Ductile regime dicing has been used to machine a variety of optical materials to produce waveguides for lasers, multimode interference devices and non-linear devices. However, few papers discuss the properties of the machining, either qualitatively or quantitatively. In this work ductile regime dicing of germanium, Yttrium Aluminum Garnet (YAG), lithium niobate and silicon for photonic applications are reported. Machining parameters are discussed, surface micrographs shown, and surface roughnesses are calculated for each sidewall machined. The sidewall average surface roughnesses $(\mathrm{Sa})$ were measured to be $2.1 \mathrm{~nm}$ for germanium, $3.5 \mathrm{~nm}$ for YAG, $7.9 \mathrm{~nm}$ for lithium niobate and $8.6 \mathrm{~nm}$ for silicon.
\end{abstract}

Keywords: dicing, ductile mode machining, germanium, YAG, lithium niobate, silicon, planar integrated optics

\section{INTRODUCTION}

It has been shown in our previous works ${ }^{1-3}$ that ductile mode dicing of silica can produce smooth, chip-free sidewall surfaces with a surface roughness as low as $4.9 \mathrm{~nm}(\mathrm{Sa})$. Within this study the focus will be on the application of ductile dicing to important optical materials such as germanium, YAG, lithium niobate and silicon. This work indicates dicing machining parameters and both sidewall surface micrographs and metrology will be presented. Conventionally, optical materials such as germanium, YAG and lithium niobate are difficult to machine, especially for optical applications. Precision dicing, and especially dicing within the ductile regime, has become interesting for the fabrication of photonic devices. Micromachined photonic structures produced via dicing include: free space input/output facets in silica-onsilicon $^{1-3}$, neodymium doped YAG ridge waveguide lasers ${ }^{4}$, lithium niobate waveguides for nonlinear processes ${ }^{5}$, silica microcantilevers ${ }^{6,7}$ and flat fiber multimode interference devices ${ }^{8}$. However, few of these reports offer quantitative or even qualitative surface analysis. Thus, this work hopes to fill some of the gaps within the literature and gives both qualitative and quantitative analysis of ductile dicing.

\section{DUCTILE DICING}

Typically used in the semiconductor industry, dicing is a versatile process that can saw into a multitude of materials and is usually used to separate individual dies from wafers. At its simplest level dicing is a precision form of sawing. A Loadpoint, MicroAce, Series 3, see figure 1 and table 1, was used throughout this paper and is a typical dicing machine. This type of dicing machines combines a high precision workbed with a low runout blade spindle. This enables the diamond impregnated blades to be accurately positioned to the micron level, so the material can be grooved or cut in two.

Table 1. Loadpoint, MicroAce, Series 3 machine characteristics.

\begin{tabular}{|l|c|c|c|c|}
\hline Machine characteristics & $\mathbf{X}$ axis $(\boldsymbol{\mu m})$ & $\mathbf{Y}$ axis $(\boldsymbol{\mu m})$ & $\mathbf{Z}$ axis $(\boldsymbol{\mu m})$ & $\boldsymbol{\theta}$ axis $\left.\mathbf{(}^{\circ}\right)$ \\
\hline Resolution & 2 & 2 & 1 & 0.005 \\
\hline
\end{tabular}




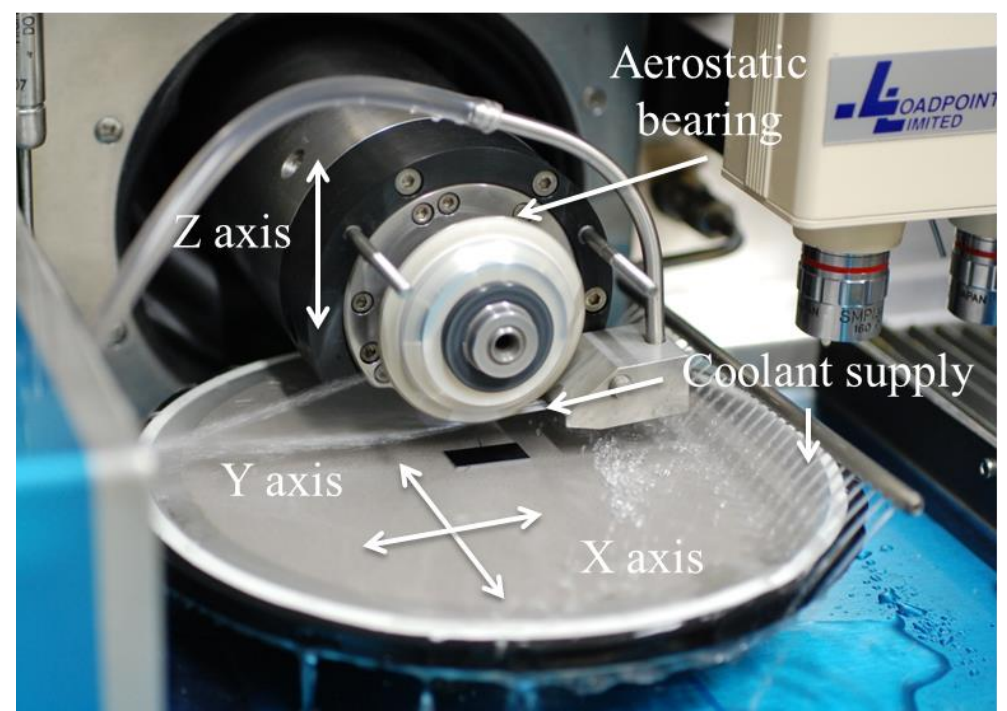

Figure 1. A Loadpoint, MicroAce, Series 3 was the dicing machine used throughout this paper. Shown are the axes of movement and the coolant supply.

To achieve smooth sidewall surfaces, with nanoscale roughness ductile dicing can be utilized. Ductile machining was first described by Bifano et al. ${ }^{9}$, where precision single point diamond turning was shown to be able to produce high quality free space optics in a variety of materials. Ductile regime machining removes material via plastic deformation of chips, typically removing hundreds of nanometers of material per tool pass. These plastically deformed chips only occur at certain machining parameters, which are related to the tool's shape, tool's material, diamond size and concentration, sample translation speed, tool rotational speed, depth of cut and sample coolant. However, if improper machining parameters are used, for instance if the translation speed is increased past a threshold which applies a shear stress that exceeds the material's plastic limit, brittle type machining will occur. Brittle regime machining causes high surface roughness, cracking and chipping, all of which are unwanted when machining for photonics applications. As shown in our previous work ${ }^{1-3}$ silica can be diced in the ductile regime with mirror like finishes, high sidewall verticality and without chipping. Within the previous work, a dicing parameter test was undertaken to explore how flame hydrolysis deposited (FHD), silica-on-silicon dices. The dicing parameters of translation speed and blade rotational speed were varied, while the blade type, depth of cut, blade dressing and sample cooling were kept constant.

The diced groove's sidewall surface roughness was measured for each machining parameter. Low surface roughness is particularly important in optics to reduce scatter losses. So, for example, in the scalar scattering theory and for normal incidence light the diffuse part of reflection can be related to RMS surface roughness by ${ }^{10}$ :

$$
\mathrm{R}_{\mathrm{d}}=\mathrm{R}_{\mathrm{o}}\left\{1-\exp \left(-\left[\frac{4 \pi \mathrm{R}_{\mathrm{q}} \mathrm{n}}{\lambda}\right]^{2}\right)\right\}
$$

where $R_{d}$ is the diffuse reflection, $R_{o}$ is the total reflection, $R_{q}$ is the RMS surface roughness, $n$ is the refractive index and $\lambda$ is the wavelength of operation. As can be seen from the equation by reducing surface roughness the amount of scatter is also reduced. The sidewall surface roughness also indicates which machining regime, ductile or brittle mode, was dominant in material removal. The measured sidewall surface roughness $(\mathrm{Sa})$ and feed rate of each different machining parameter is shown in Figure 2. 


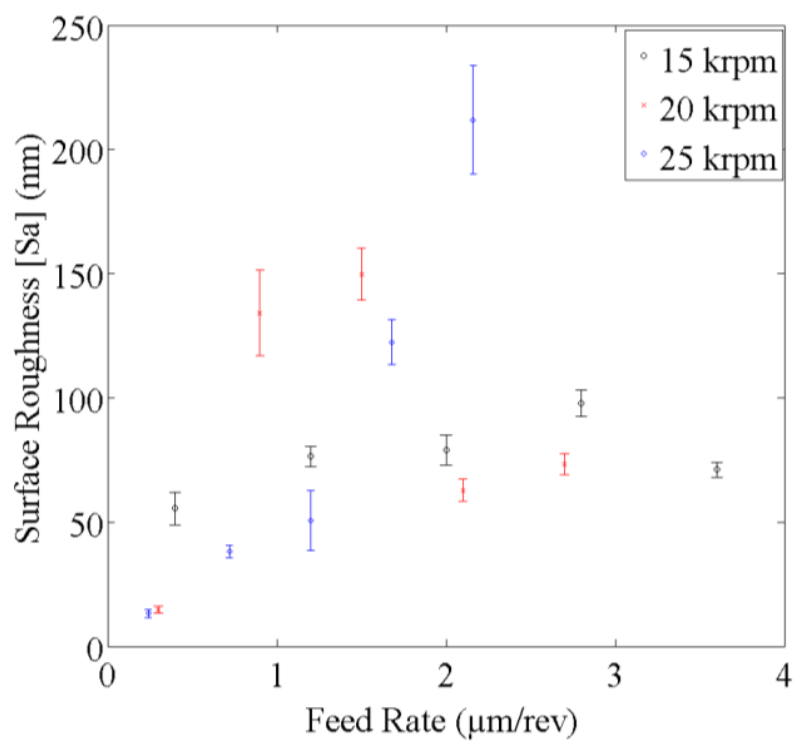

Figure 2. Data reporting dicing into FHD silica-on-silicon. The data points show the relationship between measured sidewall surface roughness $(\mathrm{Sa})$ and feed rate (with the standard error used for the error bars) ${ }^{3}$. The feed rate is determined from the translation speed and blade rotational speed and is simply the distance the sample has moved for a single rotation of the blade.

Figure 2 shows data for FHD silica, for feed rates $<0.4 \mu \mathrm{m} / \mathrm{rev}$ the surface roughness (Sa) drops $<15 \mathrm{~nm}$, demonstrating a smooth surface has been achieved. However, for feed rates $>0.4 \mu \mathrm{m} / \mathrm{rev}$ the $\mathrm{Sa}$ is $>15 \mathrm{~nm}$, indicating a rougher surface. Thus, in this work, the ductile type machining occurs for feed rates $<0.4 \mu \mathrm{m} / \mathrm{rev}$. It is apparent, that brittle machining is the dominant regime for feed rates $>0.4 \mu \mathrm{m} / \mathrm{rev}$ because of the large spread in surface roughness values and larger associated standard errors. Both the spread in data and large standard errors are caused by the stochastic nature of chipping and cracking. The smoothest sidewall surface roughnesses were achieved at a rotational speed of 20 and 25 $\mathrm{krpm}$, at a translation speed of $0.1 \mathrm{mms}^{-1}$. However, it was found that dicing directly after blade dressing further decreases the surface roughness by a factor of three, from $14.8 \mathrm{~nm}$ to $4.9 \mathrm{~nm}(\mathrm{Sa})^{3}$. From this study it was shown that low feed rates and freshly dressed blades produced the smoothest sidewalls in silica. Within the next section, ductile mode dicing will be applied to the grooving of germanium, YAG, lithium niobate and silicon, and includes microscope images, sidewall surface metrology and surface roughness measurements of each optical material machined.

\section{DUCTILE DICING OF GERMANIUM, YAG, LITHIUM NIOBATE AND SILICON}

By performing focused machining parameter tests on each optical material, germanium, YAG, lithium niobate and silicon, the dicing parameters were optimized in a similar way as discussed in section 2. Each time a new dicing parameter was performed the parameter groove had to be separated, using the 'Groove Flip Dice', to preform inspection on the sidewall as shown in figure 3. 
'Groove Flip Dice' Technique

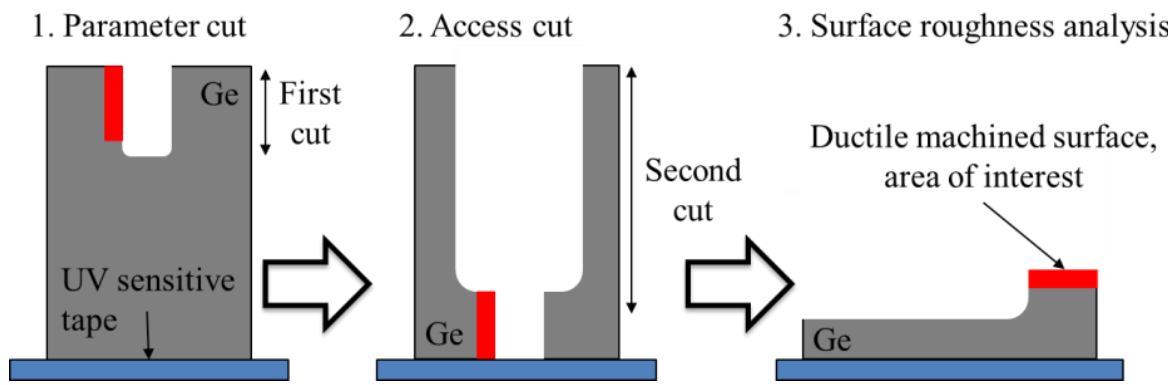

Figure 3. Cutting order to investigate the surface roughness of sidewalls made (not to scale).

Figure 3 shows the 'Groove Flip Dice' technique used to gain access to inspect the sidewall produced by the parameter dice. Firstly, the 'Groove' is cut using the parameters to be inspected, the chip is then reversed or 'Flipped' and the groove is separated by a 'Dice'. A typical 'Dice' would use a resin bonded blade (Disco RO8100848202 SM SD800 $\mathrm{R} 13 \mathrm{~B} 01 \mathrm{0.1}$ ), with a diameter of $76.2 \mathrm{~mm}$, a $100 \mu \mathrm{m}$ width and a \#800 grit size. Dressing of this blade was carried out using 75 by $75 \mathrm{~mm}$ square of silicon carbide, with a depth of cut of $100 \mu \mathrm{m}$, at a blade rotational speed of $20 \mathrm{krpm}$, a translation speed of $50 \mathrm{mms}^{-1}$ for forty passes. The dicing procedure typically used a depth of cut of $\sim 1 \mathrm{~mm}$, at a blade rotational speed of $20 \mathrm{krpm}$, with a translation speed of $0.5 \mathrm{mms}^{-1}$. This then allows the sidewall to be easily accessed by either contact or non-contact means to determine the surface roughness. Within this abstract, inspection on the sidewall was conducted visually by microscope and surface roughnesses were measured using a white light interferometer. The white light interferometer used throughout, was a Zemetrics, ZeScope. The ZeScope has a spatial resolution of $1 \mathrm{~nm}$ in the $\mathrm{Z}$ direction and a lateral resolution of $\sim 500 \mathrm{~nm}$ in $\mathrm{X}$ and $\mathrm{Y}$ when using the 50x objective, which corresponds to the diffraction limit of the lens. Polynomial leveling was applied before the areal (three dimensional) average surface roughness $(\mathrm{Sa})$ and areal (three dimensional) root mean squared surface roughness $(\mathrm{Sq})$ was calculated using the metrology software (Image Metrology, SPIP). Each of the white light interferometer plots share the same color scale for easy comparison. The ZeScope was used to collect surface metrology data on each grooved sidewall, primarily because of the speed of acquisition compared to that of an atomic force microscope (AFM) for large areas.

\section{DICING PARAMETERS AND METROLOGY}

The dicing parameters of translation speed, blade rotational speed, depth of cut, grit size, blade bond material and blade dressing are given for each optical material machined. The only constant parameter throughout these experiments was the use of $1.0 \mathrm{l} / \mathrm{min}$ of deionized water with an added surfactant for sample cooling. Silica is six on the Mohs hardness scale, while germanium, YAG, lithium niobate and silicon are five, eight, five and six ${ }^{11}$, respectively on the Mohs scale. Thus, as all of the optical materials have a similar hardness, or are harder than silica, the dicing parameter optimization starts at values found for ductile dicing of silica, as discussed in section 2. Similar dicing blades, Disco ZH05, were used throughout except for the very hard YAG where harder wearing blades were utilized. Dressing routines were taken on advisement from the blade manufacture (Disco). The most favorable dicing parameters for each optical material, germanium, YAG, lithium niobate and silicon, are given below.

Germanium is five ${ }^{11}$ on the Mohs hardness scale. We found the best machining parameters used a Disco ZH05-SD5000N1-50 BB blade. This nickel bonded blade had a diameter of $\sim 54.5 \mathrm{~mm}$, a $20-25 \mu \mathrm{m}$ width, grit size of \#5000 ( 0.5-3 $\mu \mathrm{m}$ diamond size) and the lowest grit concentration for this blade type. Dressing of the blade used a $75 \mathrm{by} 75 \mathrm{~mm}$, Disco F50 board. 30 passes were made at a depth of cut of $\sim 200 \mu \mathrm{m}$, at a blade rotational speed of $30 \mathrm{krpm}$, with a translation speed of $10 \mathrm{mms}^{-1}$ and an additional 15 passes were made at a depth of cut of $\sim 60 \mu \mathrm{m}$, with a blade rotational speed of 30 $\mathrm{krpm}$ and a translation speed of $70 \mathrm{mms}^{-1}$. The best results found for machining germanium used a depth of cut of $\sim 60$ $\mu \mathrm{m}$, at a blade rotational speed of $20 \mathrm{krpm}$ and a translation speed of $0.1 \mathrm{mms}^{-1}$, the results are shown in table 2 . 
Table 2. Germanium machined without any defects, a very smooth sidewall was generated. The surface roughness calculated for the $15 \times 15 \mu \mathrm{m}$ sample was $\mathrm{Sa}=2.1 \mathrm{~nm}$ and $\mathrm{Sq}=2.6 \mathrm{~nm}$.

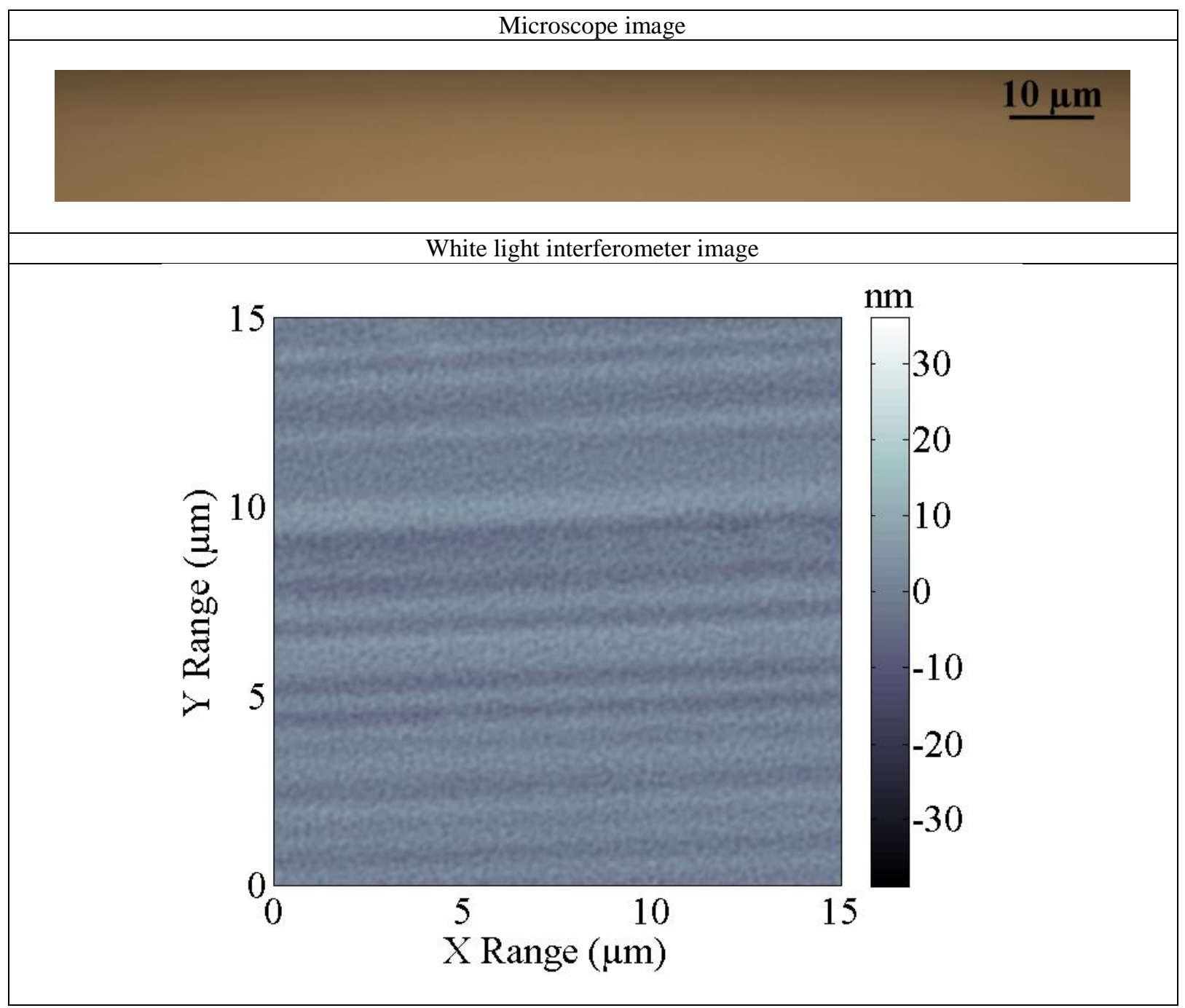

Table 2 shows high quality ductile machining of germanium. The microscope image shows no pitting, chipping or cracking. Surface metrology showed for a $15 \times 15 \mu \mathrm{m}$ sample the $\mathrm{Sa}=2.1 \mathrm{~nm}$ and $\mathrm{Sq}=2.6 \mathrm{~nm}$ was measured but for a larger $\sim 50 \mathrm{x} 90 \mu \mathrm{m}$ sample the roughness parameters increased to $\mathrm{Sa}=4.2 \mathrm{~nm}$ and $\mathrm{Sq}=5.3 \mathrm{~nm}$.

YAG is eight ${ }^{11}$ on the Mohs hardness scale and is thus the hardest material machined within this study. The best YAG machining used a Disco VT07-SD3000-VC300-50 77x0.25xA2x40L blade. The vitrified bonded blade had a diameter of $\sim 77 \mathrm{~mm}$, a $\sim 250 \mu \mathrm{m}$ width, grit size of \#3000 and the lowest diamond grit concentration for this blade type. Dressing of the blade used a 75 by $75 \mathrm{~mm}$, Disco BGC0617 board. 35 passes were made at a depth of cut of $\sim 160 \mu \mathrm{m}$, at a blade rotational speed of $13 \mathrm{krpm}$, with a translation speed of $10 \mathrm{mms}^{-1}$. Machining of the YAG used a depth of cut of $\sim 30 \mu \mathrm{m}$, at a blade rotational speed of $9 \mathrm{krpm}$, with a translation speed of $0.1 \mathrm{mms}^{-1}$. The results are shown in table 3 . 
Table 3. YAG machined with few defects, a smooth sidewall was generated. The surface roughness calculated for the $15 \times 15$ $\mu \mathrm{m}$ sample was $\mathrm{Sa}=3.5 \mathrm{~nm}$ and $\mathrm{Sq}=4.4 \mathrm{~nm}$.

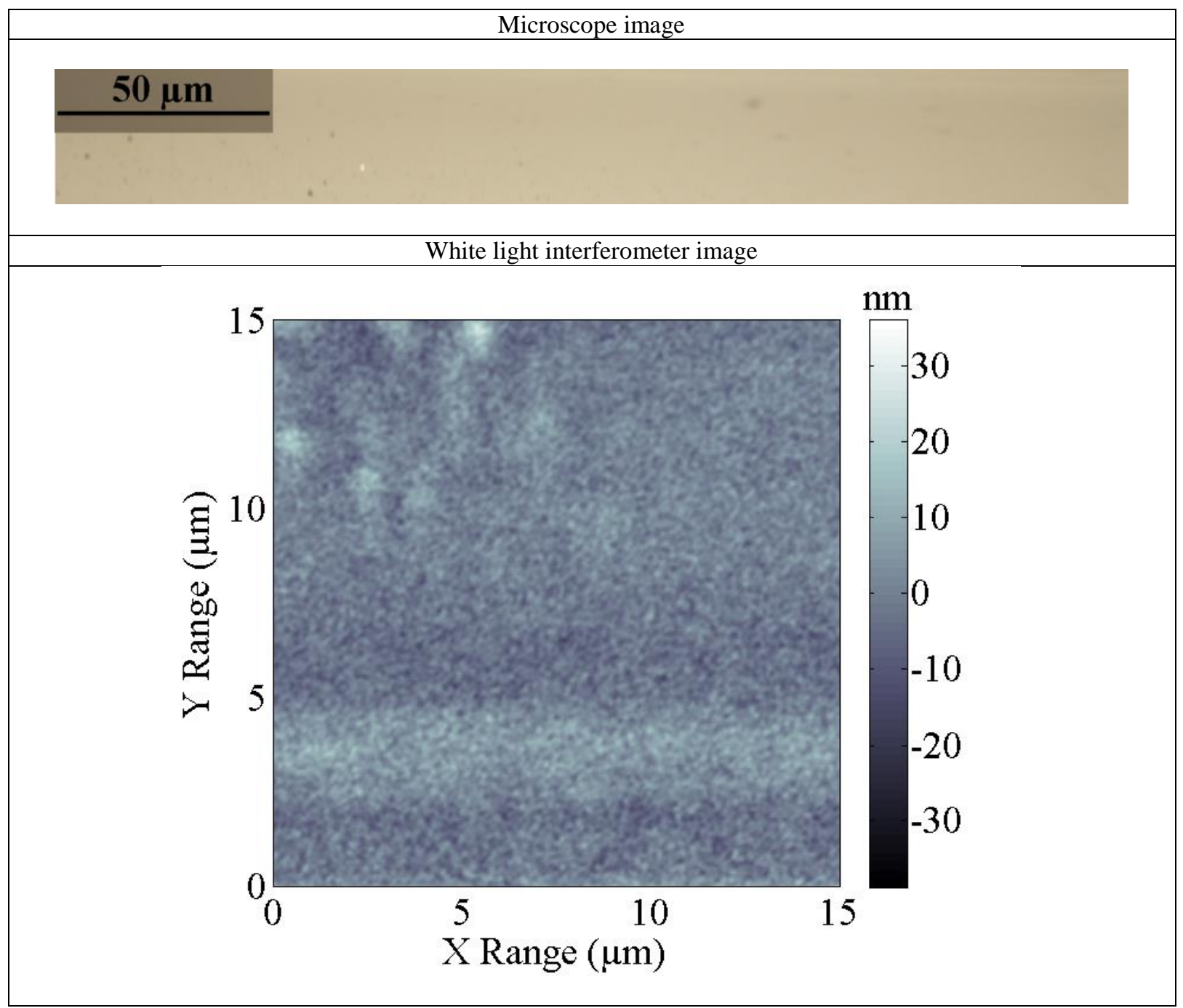

Table 3 shows another good quality surface produced this time in YAG. The microscope image shows some pitting on the micron size (lateral dimension) but no chipping or cracking. Surface metrology showed for a $15 \times 15 \mu \mathrm{m}$ sample a $\mathrm{Sa}=3.5 \mathrm{~nm}$ and $\mathrm{Sq}=4.4 \mathrm{~nm}$ was calculated. For a larger $\sim 30 \mathrm{x} 90 \mu \mathrm{m}$ sample, a $\mathrm{Sa}=7.5 \mathrm{~nm}$ and $\mathrm{Sq}=11.6$ $\mathrm{nm}$ was calculated.

Lithium niobate is five ${ }^{11}$ on the Mohs hardness scale. The best dicing procedure used a Disco ZH05-SD5000-N1-50 BA blade. The nickel bonded blade had a diameter of $\sim 54.5 \mathrm{~mm}$, a 15-20 $\mu \mathrm{m}$ width, a grit size of \#5000 $(\sim 0.5-3 \mu \mathrm{m}$ in size) and the lowest grit concentration for this blade type. Dressing of the blade used a $150 \mathrm{~mm}$ silicon wafer, with a depth of cut of $\sim 60 \mu \mathrm{m}$, at a blade rotational speed of $20 \mathrm{krpm}$, with a translation speed of $1 \mathrm{mms}^{-1}$ for three passes and $3 \mathrm{mms}^{-1}$ for a further three passes. Machining of the lithium niobate used a depth of cut of $\sim 60 \mu \mathrm{m}$, at a blade rotational speed of $20 \mathrm{krpm}$, with a translation speed of $0.1 \mathrm{mms}^{-1}$. The results are shown in table 4 . 
Table 4. Lithium niobate machined with few defects and a smooth surface was generated. The surface roughness calculated for the $15 \times 15 \mu \mathrm{m}$ sample was $\mathrm{Sa}=7.9 \mathrm{~nm}$ and $\mathrm{Sq}=9.7 \mathrm{~nm}$.

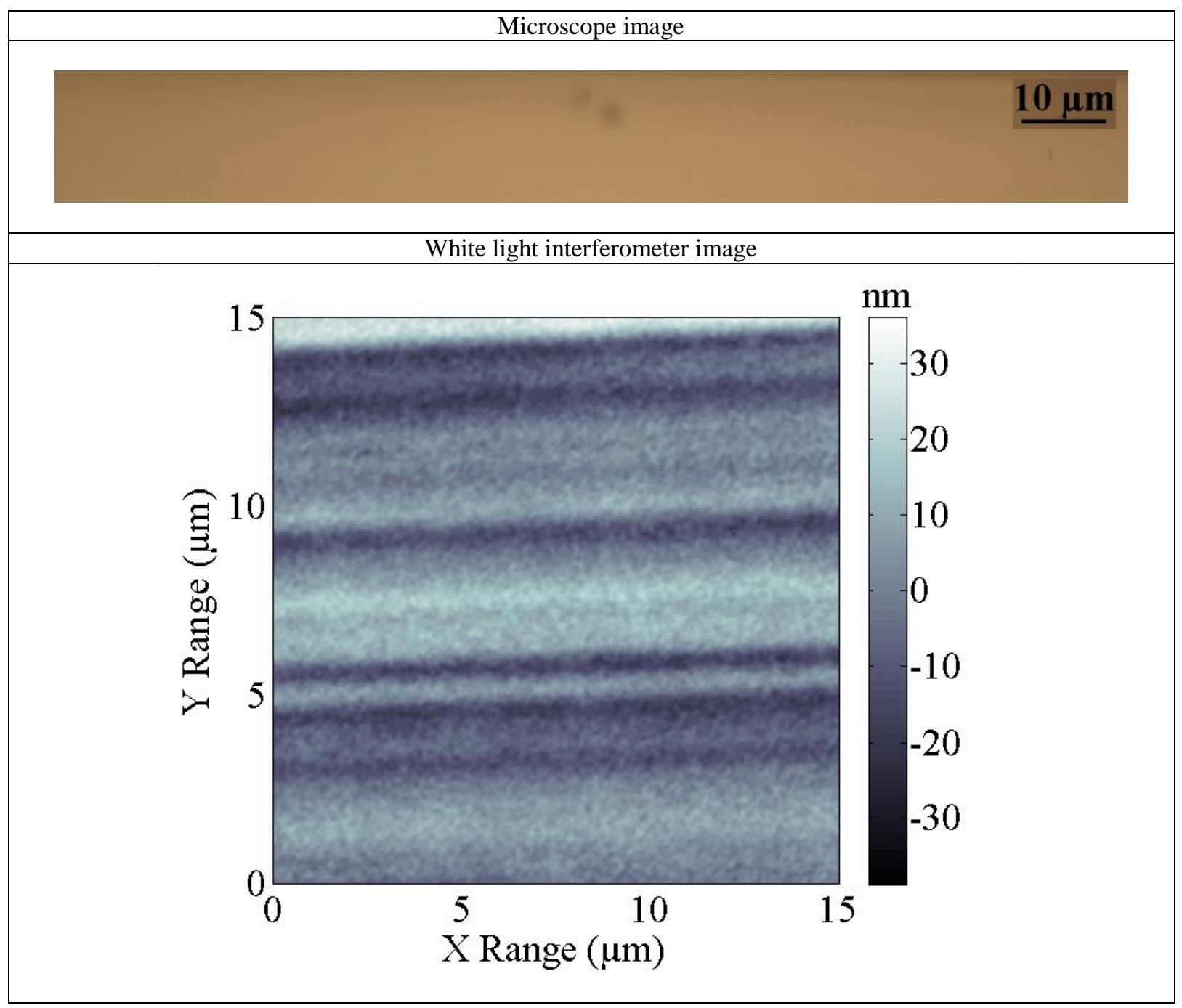

Table 4 shows good quality dicing of lithium niobate. The microscope image shows little pitting and no chipping or cracking. Surface metrology showed for a $15 \times 15 \mu \mathrm{m}$ sample the $\mathrm{Sa}=7.9 \mathrm{~nm}$ and $\mathrm{Sq}=9.7 \mathrm{~nm}$ was calculated. A larger $\sim 50 \times 90 \mu \mathrm{m}$ sample yielded a $\mathrm{Sa}=10.1 \mathrm{~nm}$ and $\mathrm{Sq}=13.1 \mathrm{~nm}$.

Silicon is $\operatorname{six}^{11}$ on the Mohs hardness scale. The best machining parameters used the same blade as used for the germanium. Dressing of the blade used a 75 by $75 \mathrm{~mm}$, Disco F50 board. 30 passes was made at a depth of cut of $\sim 200 \mu \mathrm{m}$, at a blade rotational speed of $25 \mathrm{krpm}$, with a translation speed of $10 \mathrm{mms}^{-1}$ and 15 passes a depth of cut of $\sim 60 \mu \mathrm{m}$, at a blade rotational speed of $25 \mathrm{krpm}$, with a translation speed of $70 \mathrm{mms}^{-1}$. Machining of the silicon used a depth of cut of $\sim 60 \mu \mathrm{m}$, at a blade rotational speed of $25 \mathrm{krpm}$, with a translation speed of $0.1 \mathrm{mms}^{-1}$. The results are shown in table 5 . 
Table 5. Silicon machined with some signs of pitting. The surface roughness calculated for the $15 \times 15 \mu \mathrm{m}$ sample was $\mathrm{Sa}=$ $8.6 \mathrm{~nm}$ and $\mathrm{Sq}=10.6 \mathrm{~nm}$.

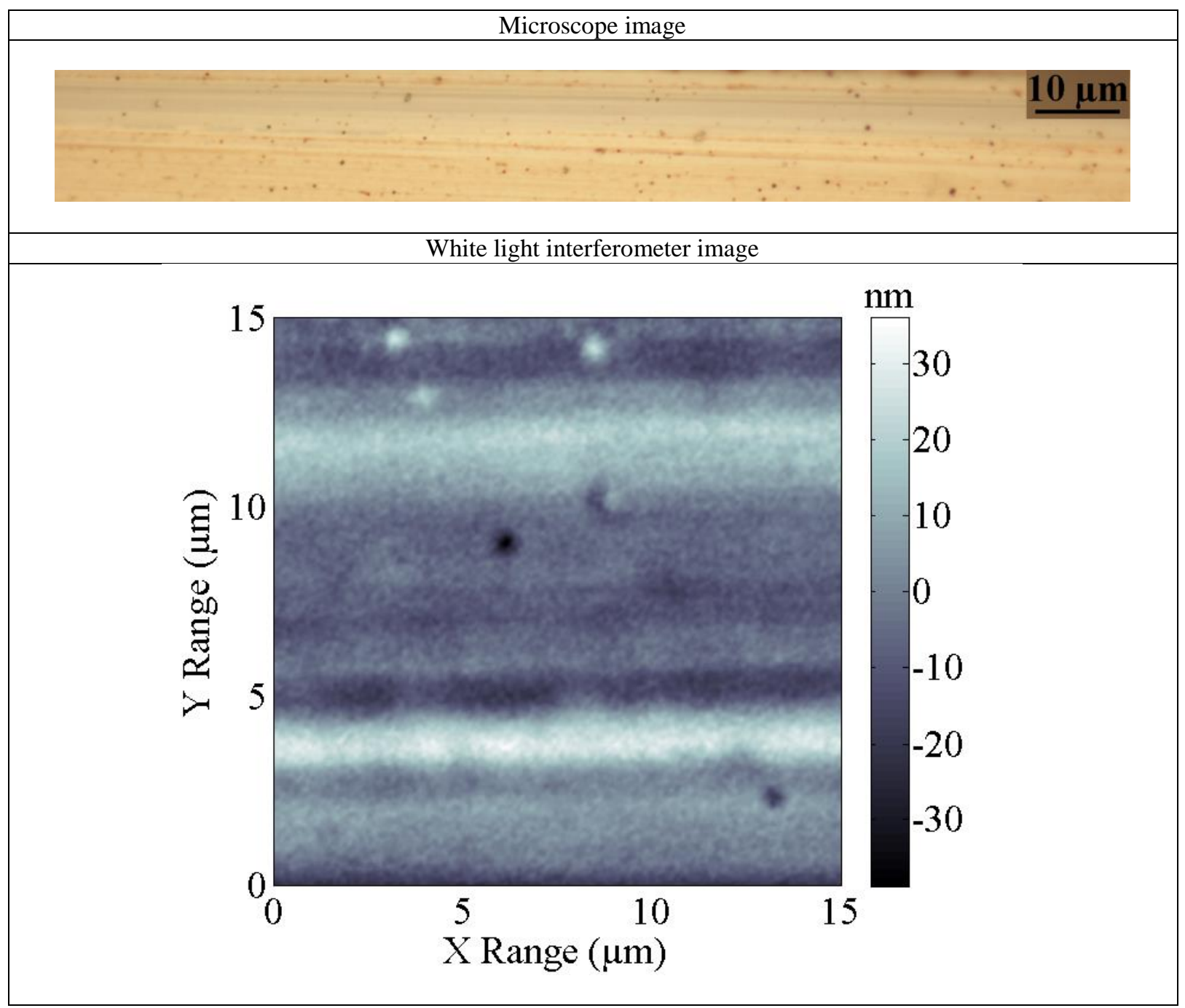

Table 5 shows fair machining of silicon. The microscope image does show pitting on the order of $0.5-2 \mu \mathrm{m}$ but no chipping or cracking. Surface metrology showed for a $15 \times 15 \mu \mathrm{m}$ sample a $\mathrm{Sa}=8.6 \mathrm{~nm}$ and $\mathrm{Sq}=10.6 \mathrm{~nm}$, while a larger $\sim 17 \times 90 \mu \mathrm{m}$ sample produced a $\mathrm{Sa}=10.1 \mathrm{~nm}$ and $\mathrm{Sq}=12.0 \mathrm{~nm}$.

\section{CONCLUSIONS}

The most favorable dicing machining parameters have been shown for machining germanium, YAG, lithium niobate and silicon to create a smooth finish via ductile dicing. Once diced, the sidewall's average surface roughnesses (Sa) was measured, by a white light interferometer, the best results being: $2.1 \mathrm{~nm}, 3.5 \mathrm{~nm}, 7.9 \mathrm{~nm}, 8.6 \mathrm{~nm}(15 \mathrm{x} 15 \mu \mathrm{m}$ samples $)$ for a germanium, YAG, lithium niobate and silicon, respectively. The results indicate that dicing can yield surfaces with high optical quality, and low levels of surface roughness. The approach also gives high surface verticality and allows very deep structures (compared to etching technology) to be achieved. 


\section{REFERENCES}

[1] Carpenter, L.G., Rogers, H.L., Holmes, C., Gates, J.C., and Smith, P.G.R., "Polish-like facet preparation via dicing for silica integrated optics," SPIE Photonics West, 2013 (2013).

[2] Carpenter, L.G., Rogers, H.L., Holmes, C., Gates, J.C., and Smith, P.G.R., "Facet Machining of Silica Waveguides with Nanoscale Roughness without Polishing or Lapping," CLEO-Europe/IQEC 2013 Munich 12 16 May 2013 (2013).

[3] Carpenter, L.G., Rogers, H.L., Cooper, P.A., Holmes, C., Gates, J.C., and Smith, P.G.R., "Low optical-loss facet preparation for silica-on-silicon photonics using the ductile dicing regime," Journal of Physics D: Applied Physics 46(47), 475103 (2013).

[4] Jia, Y., Rüter, C.E., Akhmadaliev, S., Zhou, S., Chen, F., and Kip, D., "Ridge waveguide lasers in Nd:YAG crystals produced by combining swift heavy ion irradiation and precise diamond blade dicing," Optical Materials Express 3(4), 433-438 (2013).

[5] Courjal, N., Guichardaz, B., Ulliac, G., Rauch, J.-Y., Sadani, B., Lu, H.-H., and Bernal, M.-P., "High aspect ratio lithium niobate ridge waveguides fabricated by optical grade dicing," Journal of Physics D: Applied Physics 44(30), 305101 (2011)

[6] Carpenter, L.G., Holmes, C., Rogers, H.L., Smith, P.G.R., and Gates, J.C., "Integrated optic glass microcantilevers with Bragg grating interrogation," Optics Express 18(22), 23296-23301 (2010).

[7] Carpenter, L.G., Holmes, C., Snow, B.D., Gates, J.C., and Smith, P.G.R., "Photonic Microcantilevers With Interferometric Bragg Grating Interrogation,” IEEE Photonics Journal 4(5), 1387-1395 (2012).

[8] Ambran, S., Holmes, C., Gates, J.C., Webb, A.S., Carpenter, L.G., Adikan, F.R.M., Smith, P.G.R., and Sahu, J.K., "Fabrication of a Multimode Interference Device in a Low-Loss Flat-Fiber Platform Using Physical Micromachining Technique," Journal of Lightwave Technology 30(17), 2870-2875 (2012).

[9] Bifano, T.G., Dow, T., and Scattergood, R.O., "Ductile-regime grinding: a new technology for machining brittle materials," Journal of Engineering for Industry (Transactions of the ASME) 113(2), 184-189 (1991).

[10] Bennett, H.E., and Porteus, J.O., "Relation Between Surface Roughness and Specular Reflectance at Normal Incidence,” Journal of Optical Society of America 51(2), 123-130 (1961).

[11] Fynn, G.W., and Powell, W.J.A., [Cutting and Polishing Optical and Electronic Materials] , 2nd ed., Institute of Physics Publishing Inc., Bristol, 170-181 (1988). 